\title{
Assessment of Postural effect on Work Related Musculoskeletal Disorders and Back Muscle Fatigue among the Goldsmiths of India
}

\begin{abstract}
:
Background: Musculoskeletal disorders (MSD) may be defined as injuries and disorders of the muscles, Tirthankar Ghosh nerves, tendons, ligaments, joints, cartilage and spinal disc. This may occur due to improper physical work activities or appalling workplace conditions. Awkward or extreme postures are less efficient than posture keep joints near the center of their range of motion. Objective: The objective of the current study was to assessment of postural effect on work related musculoskeletal disorders and back muscle fatigue among the goldsmiths of India. Methods: In this current study, the experiment was performed on 100 male goldsmiths. A detailed questionnaire study on discomfort feeling was done and analysis of body posture by Rapid Upper Limb Assessment was done to evaluate the work stress during their job. Electromyographic activity was collected from ten major trunk muscles sites which consist of right and left muscle. Result: From the analysis, it was revealed that musculoskeletal disorders were the major problem of the goldsmiths. Moreover questionnaire study revealed that most of the workers were affected by pain at Neck $(80 \%)$, Low back $(91 \%)$, Wrist $(45 \%)$, Shoulder $(20 \%)$. Decreased in RMS and MedF of all the ten major trunk muscles were observed at the end of the every work cycle, which indicating that muscular fatigue was induced by the Gold Smiths tasks. Conclusion: From this study it can be concluded that the goldsmiths are working in awkward and forward bending postures for prolonged period of time with the potential risks of musculoskeletal disorders primarily affecting the low-back and neck region of the body. This can be attributed by the improper design of the workstation.
\end{abstract}

Key Words: EMG, Goldsmith; MSD; Posture; RULA
Department of Physiology; Maitri Educational Society; Durg; Chhattisgarh.

() 2015 IJOSH All rights reserved.

\section{Introduction}

Many people have experienced muscle fatigue in daily life, including low back and shoulder pain. The degree of such pain can be estimated by a patient's subjective symptoms or by examining muscle stiffness utilizing manual palpation. These methods, however, are not necessarily reliable, and manual palpation is particularly dependent upon operator experience. Quantifying muscle fatigue is vital to the suppression or reduction of pain. It has been demonstrated that in local muscle fatigue, the myoelectric frequency shifts towards a lower frequency band with both static and dynamic contractions [1].

Musculoskeletal disorders (MSD) can be caused by heavy physical work, static work postures, frequent bending and twisting, lifting, pushing and pulling, repetitive work, vibration and psychological and psychosocial stress [10]. Musculoskeletal disorder is commonly caused by overexertion, muscle strain and repetitive strain. The risk of disorder also directly related to the some number and speed of movements and the amount of force exerted with each movement. A task with high repetition and poor postures may result in a significant number of complaints or injuries [11]. A person working from an extreme or awkward posture will have to use more force to accomplish the same amount of work compared to using a neutral posture, which in turn affects muscle loading and compressive forces on the internal vertebral disc $[12,13]$. The amount and quality of forward-bent posture and the techniques of work influence the compressive force on the vertebral discs and the electromyography of erector spine muscles [12].

Based on biomechanical models of the spine, it was proposed that spinal stabilization should be considered the result of highly-coordinated muscular activation interacting with passive elements[3]. However sufficient spinal stability is usually 
achieved by modest coordinated co-contraction of the anterior and posterior trunk muscles [3]. Spinal stability is also highly dependent on spinal load and posture [4] as well as task requirements [5]. Instability of the lumbar spine has been suggested to be both a cause and a consequence of low back pain (LBP)[3].

Surface EMG techniques have been extensively applied to the analysis of low back muscles, both in healthy subjects and low back pain patients $[2,3,4,5,6]$. Surface EMG analysis has shown advantages for fatigue assessment and has been applied for classifying healthy subjects and low back pain patients [3], trained and non-trained subjects [4], subjects under rehabilitation treatments [5]; moreover, surface EMG provided evidence of physiological phenomena related to the back musculature [7] and myoelectric manifestations of muscle fatigue were shown to be predictor of the trunk extensor endurance time [8], thus reflecting mechanical fatigue.

In India Gold ornament making industries are one of the widespread small-scale industries. A large number of goldsmiths are working there for prolonged period in a semi-confined workstation. In previous study [17] it was found that goldsmiths were highly affected by improper body posture and workload. Twisting, bending, and over-reaching are the resultant of poorly designed workstation. Moreover, lack of proper illumination at work site also exerts an additional adverse effect on the health of the goldsmiths.

The purpose of the current study was to assessment of postural effect on work related musculoskeletal disorders and back muscle fatigue among the goldsmiths of India.

\section{Methods}

For this current study 100 male goldsmiths were randomly selected from Davangere district of Karnataka, India

\section{Questionnaire study:}

Modifiied Nordic questionnaire [20] was applied which included questions emphasizing individual details, type of work, musculoskeletal disorder symptoms, history of accidents etc. to investigate the discomfort of work. In our present study this type of questionnaire was applied to evaluate the general physical activity, task variety, work stress, working environment and workstation design of the goldsmiths.

\section{Analysis of Working Posture:}

The maintenance of posture and the support of load are particular examples of static work. To analyze posture, measurement of the angles between the body parts, distribution of masses of body parts, the forces exerted on the environment during the posture, the length of the time during which specific posture is held and the effect on the person should be taken into account. A procedure was developed by McAtamney and Corlett [21] to assess the exposure of people to postures, forces and muscle activities known to contribute to Upper Limb Disorders
(ULD). This Rapid Upper Limb Assessment (RULA) technique was used here to assess the postural discomfort of the goldsmith at their average working posture.

\section{Electromyography (EMG):}

Electromyographic (EMG) activity was collected through the use of bi-polar silver-silver chloride electrodes that have $4 \mathrm{~mm}$ diameter. Gel filled disposable vinyl electrodes (EL 503) and Biopac Student Lab, MP30B - CE (California, USA) were used for each recording. The electrodes were placed at the ten major trunk muscles sites which consist of right and left muscle pairs of trapezius; latissimus dorsi; teres minor; teres major and erector spinae muscles. The raw EMG signals were pre-amplified, high-passed filtered at $10 \mathrm{~Hz}$, low-passed filtered at $500 \mathrm{~Hz}$, rectified, and smoothed with a low pass filter of $20 \mathrm{~ms}$ sliding window. The Amplitude of the rectified EMG over a time interval was recorded as Root Mean Square (RMS). The frequency content of each recording in each segment was analyzed by Fast Fourier Transform analysis (FFT) and the power spectrum was quantified by measuring Median Frequency (MDF). All the data were collected for two times of a work cycle as starting of work and end of work.

Muscle fatigue during the work was assessed through power spectral analysis of the EMG data. The rate of decline of Median Frequency (MedF) and the rate of EMG amplitude (RMS) were calculated to confirm that muscle fatigue was induced correctly.

To ensure that the sEMG protocols were complied with, we attached electrodes on respective muscles and a physiotherapist was consulted before the evaluation was carried out. The setting of the sEMG system during the measurement was based on sEMG for the Non-Invasive Assessment of Muscles [27]. The settings were as follows:

- EMG electrodes: Surface electrode $\mathrm{Ag} / \mathrm{AgCl}, 20 \mathrm{~mm}$ diameter

- Distance between electrodes: $25 \mathrm{~mm}$

- Skin preparation: Shaved, clean, gently abraded, and scrubbed with alcohol

- Common mode rejection rate: $110 \mathrm{~dB}$

- $\quad$ Filter: Band pass filter $(85-500 \mathrm{~Hz})$

- $\quad$ Sampling rate: $1,000 \mathrm{~Hz}$

The measurements of muscle activity were conducted based on real-time monitoring. All electrodes were connected to a data logger and the electromyography signals from the data logger are monitored through a lap top screen using a wireless network. Before starting the muscle activity measurement, the personal details of the subject are recorded in the MegaWin software. At the beginning of the measurement, the subject was given sufficient time to familiarize and practice the sEMG system. The subject was informed that he had to perform the process 


\section{Statistical analysis:}

Repeated-measures analysis of variance (ANOVA) statistical analyses were performed for the Trunk muscle's EMG amplitude (RMS) \& Median Frequency to explore whether differences exist between the two times of a work cycle as starting of work and end of work. For ANOVA the F ratio was computed to find out the significant difference between the changes of EMG and muscle fatigue during the work. Statistical analysis was performed using the statistical package PRIMER OF BIOSTATISTICS (Primer of Biostatistics 5.0.msi, Msi Version 1.20.1827.0, Primer for Windows, McGraw-Hill).

\section{Results}

Demographic factors of goldsmiths, relating to the study population, including age, weight and in Table 1.

Table 1: General physical characteristics of the workers

\begin{tabular}{|c|c|c|c|c|}
\hline Variables & $\begin{array}{c}\text { Age } \\
(\text { years })\end{array}$ & Height $(\mathbf{c m})$ & Weight $(\mathbf{k g})$ & BMI $\left(\mathbf{k g} / \mathbf{m}^{2}\right)$ \\
\hline $\begin{array}{c}\text { Gold } \\
\text { Smiths }\end{array}$ & $32( \pm 8.21)$ & $163.25( \pm 5.25)$ & $56.36( \pm 9.07)$ & $21.36( \pm 2.75)$ \\
\hline
\end{tabular}

The mean age of the workers being 32 years have average $163.25 \mathrm{~cm}$ height and $56.36 \mathrm{~kg}$ weight. The years of experience of the workers were calculated from questionnaire and on average goldsmiths have 13.2 years of experience. The daily work schedule including the average duration of work was 12 hrs $( \pm 2.11)$ that varies on the demand of work and rest $1 \mathrm{hr}$ $( \pm 1.00)$. The number of working days in a week is six days (Table 2).

Table 2: General information of the workers

\begin{tabular}{|c|c|c|c|c|}
\hline Variables & $\begin{array}{c}\text { Years of } \\
\text { Experience }\end{array}$ & $\begin{array}{c}\text { Duration of } \\
\text { work } \\
\text { Per day } \\
\text { (in hour) }\end{array}$ & $\begin{array}{c}\text { Duration of } \\
\text { rest } \\
\text { Per day } \\
\text { (in hour) }\end{array}$ & $\begin{array}{c}\text { Number of } \\
\text { working } \\
\text { days in a } \\
\text { week }\end{array}$ \\
\hline $\begin{array}{c}\text { Gold } \\
\text { Smiths }\end{array}$ & $14.2( \pm 2.4)$ & $12( \pm 2.1)$ & $1( \pm 1.0)$ & 6 \\
\hline
\end{tabular}

The analysis of questionnaire (Table 3 ) showed that $100 \%$ of the workers performed skillful activity. As large as $93 \%$ of them reported that they have to sit in one place for a long time while working. $57 \%$ of the workers agreed that there exists rigidity in work methods and conditions. $82 \%$ of the workers reported that their job demand a target specific productivity. $100 \%$ of the workers reported that their job requires repetitive motion of body segments, particularly the movement of the hands. During questionnaire study $100 \%$ goldsmiths were reported the feeling of discomfort. It was observed that the feelings of discomfort among the goldsmiths were mainly related to musculoskeletal disorders like pain at Neck (80\%), Low back (91\%), Wrist $(45 \%)$, Shoulder (20\%).
Table 3: Responses of Questionnaire

\begin{tabular}{|c|c|c|}
\hline & Responses & Gold Smiths \\
\hline $\begin{array}{l}\text { Job requires knowledge } \\
\text { of skillful activity }\end{array}$ & Yes & $100 \%$ \\
\hline $\begin{array}{l}\text { Workers make frequent } \\
\text { mistakes }\end{array}$ & Yes & $21 \%$ \\
\hline $\begin{array}{l}\text { Job demands frequent } \\
\text { rotation for task and place }\end{array}$ & Yes & $7 \%$ \\
\hline $\begin{array}{l}\text { Rigidity in work methods } \\
\text { and procedure }\end{array}$ & Yes & $57 \%$ \\
\hline $\begin{array}{l}\text { Work demand target } \\
\text { specific productivity }\end{array}$ & Yes & $82 \%$ \\
\hline $\begin{array}{l}\text { Worker wears (if any } \\
\text { specific type) }\end{array}$ & Yes & Nil \\
\hline $\begin{array}{l}\text { Job demands repetitive } \\
\text { motions of body } \\
\text { segments }\end{array}$ & Yes & $100 \%$ \\
\hline $\begin{array}{l}\text { Like to accept new jobs/ } \\
\text { responsibilities }\end{array}$ & Yes & $71 \%$ \\
\hline $\begin{array}{l}\text { Favor: Job rotation/ } \\
\text { Division of labor }\end{array}$ & Yes & $10 \%$ \\
\hline $\begin{array}{c}\text { Personal protective } \\
\text { devices }\end{array}$ & Yes & Nil \\
\hline
\end{tabular}

\begin{tabular}{|c|c|c|}
\hline \multicolumn{3}{|c|}{ Questionnaire Part-2 Measurement of Work Stress } \\
\hline Have you got tired easily & Yes & $57 \%$ \\
\hline $\begin{array}{l}\text { Have you been annoyed } \\
\text { and irritated easily }\end{array}$ & Yes & $32 \%$ \\
\hline Have you got bored easily & Yes & $71 \%$ \\
\hline Have you been forgetful? & Yes & $14 \%$ \\
\hline $\begin{array}{l}\text { Difficulty in falling or } \\
\text { staying asleep }\end{array}$ & Yes & $7 \%$ \\
\hline \multirow{3}{*}{$\begin{array}{l}\text { Do you in your work often } \\
\text { have to: Lift, pull or push } \\
\text { and carry loads (more } \\
\text { than } 20 \mathrm{~kg} \text { ) }\end{array}$} & Lift & $16 \%$ \\
\hline & Push & $6 \%$ \\
\hline & Carry & $8 \%$ \\
\hline \multirow{2}{*}{ Lifting behavior } & Alone & $100 \%$ \\
\hline & With others & Nil \\
\hline \multirow{2}{*}{$\begin{array}{c}\text { Do you often have to } \\
\text { stand, sit for a prolong } \\
\text { time }\end{array}$} & Stand & $9 \%$ \\
\hline & Sit & $91 \%$ \\
\hline $\begin{array}{c}\text { Do you feel any kind of } \\
\text { discomfort }\end{array}$ & Yes & $100 \%$ \\
\hline Discomfort at Neck & Yes & $80 \%$ \\
\hline Discomfort at Low back & Yes & $91 \%$ \\
\hline Discomfort at Wrist & Yes & $45 \%$ \\
\hline Discomfort at Shoulder & Yes & $20 \%$ \\
\hline
\end{tabular}


The average working posture of the goldsmiths at their working condition (cross-legged) was analyzed by the RULA method (Table 4). The analysis revealed that the posture requires investigation and changes immediately. This indicates that the workers are adopting awkward posture at their daily work process.

Table 4: Analysis of working posture of the Goldsmiths (By RULA method)

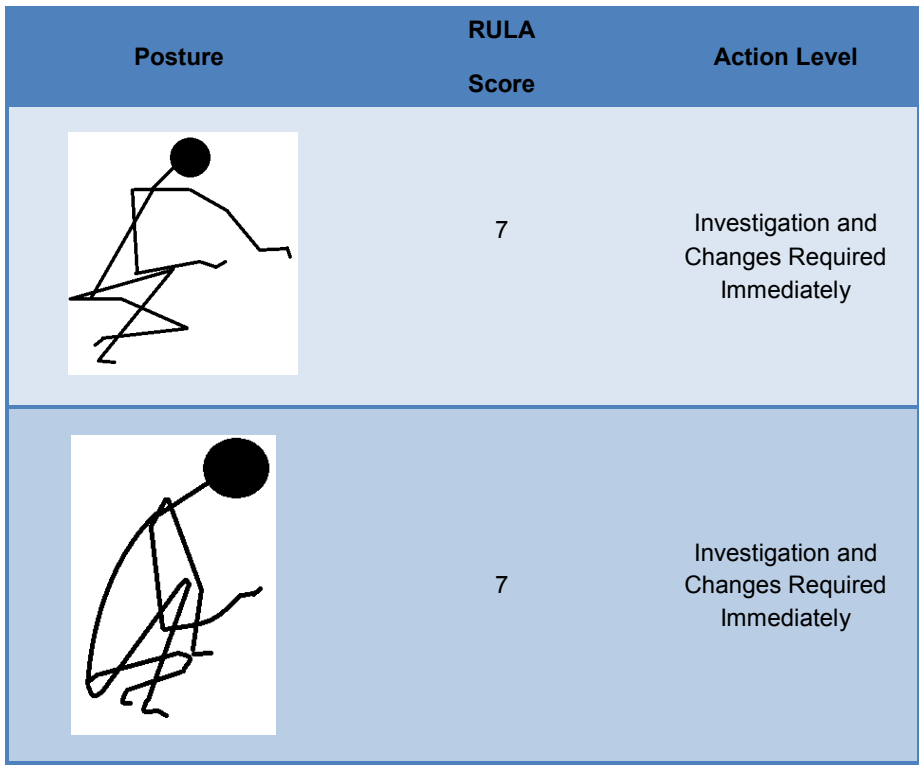

Changes in Trunk muscle's Median Frequencyl time $(\mathrm{Hz})$ of Gold Smiths during work

\begin{tabular}{|cccc|}
\hline Muscle & Starting of Work & End of Work & Anova \\
\hline R Trapezius & $79.3( \pm 8.9)$ & $54.6( \pm 13.5)$ & Significant $(p<0.05)$ \\
\hline L Trapezius & $77.5( \pm 6.2)$ & $47.3( \pm 11.5)$ & Significant $(p<0.05)$ \\
\hline R LD & $66.2( \pm 5.4)$ & $49.4( \pm 18.2)$ & Significant $(p<0.05)$ \\
\hline L LD & $64.2( \pm 8.1)$ & $47.1( \pm 13.3)$ & Significant $(p<0.05)$ \\
\hline R T minor & $48.5( \pm 9.2)$ & $37.9( \pm 11.7)$ & Significant $(p<0.05)$ \\
\hline L T minor & $42.1( \pm 7.2)$ & $29.4( \pm 11.4)$ & Significant $(p<0.05)$ \\
\hline R T major & $45.5( \pm 6.3)$ & $31.6( \pm 14.7)$ & Significant $(p<0.05)$ \\
\hline L T major & $44.2( \pm 5.2)$ & $30.1( \pm 9.6)$ & Significant $(p<0.05)$ \\
\hline R ES & $76.2( \pm 8.4)$ & $49.4( \pm 18.2)$ & Significant $(p<0.05)$ \\
\hline L ES & $69.6( \pm 5.8)$ & $41.4( \pm 8.7)$ & Significant $(p<0.05)$ \\
\hline
\end{tabular}

The changes in the Gold Smiths Trunk muscle's EMG amplitude (RMS) \& Median Frequency were computed from the recorded raw EMG signals. EMG fatigue indices (RMS, MedF) are presented in Figure 1 for both side of trunk muscles which consists of right and left muscle pairs of trapezius; latissimus dorsi; teres minor; teres major and erector spinae muscles. The mean value of Trunk muscle's EMG amplitude (RMS) \& Median Frequency were calculated for two times of a work cycle as starting of work and end of work. Decreased in RMS and MedF of all the ten major trunk muscles were observed at the end of the every work cycle, which indicates that muscular fatigue was induced by the Gold Smiths tasks.

Figure 1: Changes in Trunk muscle's EMG amplitude (RMS) \& Median Frequency of Gold Smiths
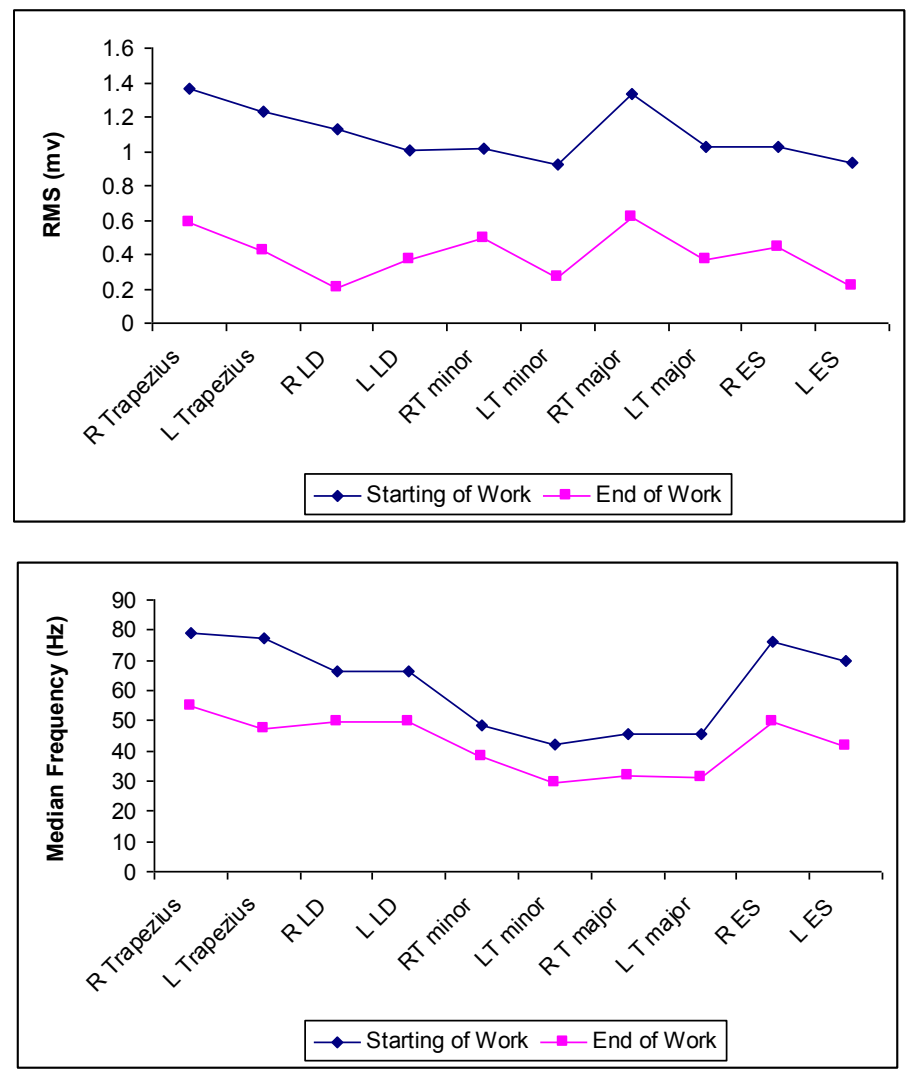

The analysis of variance (ANOVA) indicated that there was significant decrease in EMG amplitude (RMS) \& Median Frequency in all the ten major trunk muscles at the end of the every work cycle. This indicates an increase in onset of fatigue in all the ten major trunk muscles (Table 5).

Table 5: work RMS (mv)

\begin{tabular}{|llll|}
\hline \multicolumn{1}{|c}{ Muscle } & Starting of Work & End of Work & Anova \\
\hline R Trapezius & $1.36( \pm 0.79)$ & $0.58( \pm 0.11)$ & Significant $(p<0.05)$ \\
\hline L Trapezius & $1.23( \pm 0.53)$ & $0.42( \pm 0.26)$ & Significant $(p<0.05)$ \\
\hline R LD & $1.13( \pm 0.57)$ & $0.21( \pm 0.08)$ & Significant $(p<0.05)$ \\
\hline L LD & $1.01( \pm 0.27)$ & $0.37( \pm 0.11)$ & Significant $(p<0.05)$ \\
\hline R T minor & $1.02( \pm 0.39)$ & $0.49( \pm 0.06)$ & Significant $(p<0.05)$ \\
\hline L T minor & $0.92( \pm 0.17)$ & $0.27( \pm 0.12)$ & Significant $(p<0.05)$ \\
\hline R T major & $1.33( \pm 0.75)$ & $0.62( \pm 0.46)$ & Significant $(p<0.05)$ \\
\hline L T major & $1.03( \pm 0.52)$ & $0.37( \pm 0.22)$ & Significant $(p<0.05)$ \\
\hline R ES & $1.07( \pm 0.73)$ & $0.44( \pm 0.21)$ & Significant $(p<0.05)$ \\
\hline L ES & $0.93( \pm 0.63)$ & $0.22( \pm 0.06)$ & Significant $(p<0.05)$ \\
\hline
\end{tabular}




\section{Discussion}

The results of this study revealed that the goldsmiths are engaged in prolonged forward bending posture in there working condition which may lead to discomfort feeling (pain) among them. This result corroborates with the work of Gangopadhyay et al. [22, 23]. According to them the subjects working in an awkward posture for prolonged period of time lead to discomfort feeling (pain) in different parts of the body which may lead to musculoskeletal disorders among them. The current study also indicates that the goldsmith are constantly engaged in repetitive and hand intensive jobs for several years, from which they suffer from discomfort feeling in the upper extremities of the body. Similar result was found by of Gangopadhyay et al. [24], according to them highly repetitive hand intensive jobs among the brass metal workers lead to discomfort in the upper extremities. It has been also known that WMSDs are caused by multi-factorial operations of various risk factors such as poor working posture, repetitive and forceful activities and static muscle load $[25,26]$. The association of poor body postures with pain or symptoms of musculoskeletal disorders has been reported in a number of studies. [27, 28]

Various studies [14, 15, 16] found a significant association between posture variables and neck MSDs. Similarly current study finds that, $100 \%$ goldsmiths were having feeling of discomfort. It also observed that the feelings of discomfort among the goldsmiths were related to musculoskeletal disorders like pain at Neck $(80 \%)$ and Low back $(91 \%)$. This finding also corroborates with the analysis of cross-legged posture of the goldsmiths by the RULA method. It reveals that the posture requires investigation and changes immediately. This indicates that the workers by adopting awkward posture at work, most often suffer from musculoskeletal disorders particularly affecting the low back and neck region. According to them awkward posture lead to discomfort feeling (pain) in different parts of the body especially on lower back, neck, knee region of the body. From the observation and analysis of the result it can be revealed that the goldsmiths are working in awkward postures, with the potential risks of musculoskeletal disorders primarily affecting the low-back and neck region.

From the observation and analysis of the result it can be revealed that the goldsmiths are working in awkward postures, with the potential risks of musculoskeletal disorders primarily affecting the low-back and neck region. Based on biomechanical models of the spine, it was proposed that spinal stabilization should be considered the result of highly coordinated muscular activation interacting with passive elements [29]. However, sufficient spinal stability is usually achieved by modest coordinated co-contraction of the anterior and posterior trunk muscles. Spinal stability is also highly dependent on spinal load and posture [30] as well as task requirements [31]. Instability of the spine has been suggested to be a cause and a consequence of low back pain (LBP) [29].

The amount and quality of forward-bent posture and the techniques of work influence the compressive force on the vertebral discs and the electromyography of spine muscles [12]. The relationship between the force produced by the muscle or muscle activity and the amplitude of the EMG signal is relatively linear [32]. The relationship between the muscle activity and the energy content of the EMG signal within physiological limit is also linear but in fatigue state low energy content of the EMG is produced [33]. Gold smiths working activities uses ten major trunk muscles which consist of right and left muscle pairs of trapezius; latissimus dorsi; teres minor; teres major and erector spinae muscles in great extent. As they perform their work in particular posture for prolonged duration, it causes static load to trunk muscles. Surface EMG study shows the mean value of Trunk muscle's amplitude (RMS) \& Median Frequency were decreased in for all the ten major trunk muscles at the end of the every work cycle, indicating that muscular fatigue was induced by the Gold Smiths tasks.

The lower EMG power spectrum shift during fatigue is considered to be related to biochemical by-product accumulation $(\mathrm{H}+$ and lactic acid) in the muscle, which changes the action potential conduction velocity [34]. Other factors, such as firing rate of motor units, motor unit synchronization, additional recruitment of motor units, and muscle temperature influence the frequency changes. In this study, significant change in EMG parameters (MDF, RMS) was recorded at the end of a work cycle. ANOVA detected significant decrease in EMG amplitude (RMS) \& Median Frequency in all the ten major trunk muscles at the end of the every work cycle. Lower MDF shift related to fatigue is believed to be more reflected in type II fibre fatigue. Komi and Tesch [35] showed in their experiment that MDF declined significantly during fatigue in subjects with a high proportion of fast-twitch fibers, but showed only a slight decrease in those with a high proportion of slow-twitch fibers. Erector spinae muscles are composed of about $40 \%$ type II and $60 \%$ type I fibers [36]. Postural muscles contain less type II fibers than many other muscles [37], although the proportion of type II fibers tend to be larger in subjects with low back pain (LBP) [3].

\section{Conclusion}

From this study it can be concluded that the goldsmiths are working in awkward and forward bending postures for prolonged period of time with the potential risks of musculoskeletal disorders primarily affecting the low-back and neck region of the body. This can be attributed by the improper design of the workstation. Twisting, bending and over-reaching are the resultant of poorly designed workstation. These action forces effects on the spine into a non-neutral position that increase the overall discomfort, pain and muscle fatigue particularly at the lower back, neck and shoulders, which indicate that the goldsmiths are affected by work-related upper body musculoskeletal disorders. Surface EMG study also 
indicates Trunk muscle's fatigue was induced by the Gold Smiths tasks. It is also possible that these muscles are not able to provide sufficient stabilization to the vertebral units due to the fatigue. The working environment of the goldsmith also affects them to a great extent. Lack of proper illumination at work site exerts an additional adverse effect on the eyes. Thus this study indicates the appalling condition of the goldsmiths.

To overcome such problem, the existing posture can be eliminated by ergonomically modified work desk. This modification may increase the safety of the workers at the work.

\section{Recommendations}

I) Ergonomically designed adjustable work desk (work height, work space) along with adjustable chair with proper back rest should be provided to the goldsmith to avoid the forward bending and cross leg posture.

II) Provide recommended (precision job) illumination to their work site, which can reduce the visual discomfort.

III) Since prolonged sitting in cross leg posture is clearly an additional risk factor affecting the musculoskeletal system in these settings, goldsmiths should be strongly suggested to take rest pauses during work period.

\section{References}

1. De Luca CJ: Myoelectric manifestations of localized muscular fatigue in humans. Crit Rev Biomed Eng. 1984; 11: 251-279.

2. De Luca CJ: Use of the surface EMG signal for performance evaluation of back muscles. Muscle Nerve. 1993; 16: 210-216.

3. Roy SH, De Luca CJ, Casavant DA: Lumbar muscle fatigue and chronic lower back pain. Spine. 1989; 14:992-1001.

4. Roy SH, De Luca CJ, Snyder Mackler L, Emley MS, Crenshaw RL, Lyons JP: Fatigue, recovery, and low back pain in varsity rowers. Med Sci Sports Exerc. 1990; 22: 463-469.

5. Roy SH, De Luca CJ, Emley M, Buijs RJ: Spectral electromyographic assessment of back muscles in patients with low back pain undergoing rehabilitation. Spine. 1995; 20: 38-48.

6. Larivie 're $C$, Arsenault $A B$, Gagnon D, Loisel P : Surface electromyography assessment of back muscle intrinsic properties. J Electromyogr Kinesiol. 2003; 13:305- 318.

7. Merletti R, De Luca CJ, Sathyan D: Electrically evoked myoelectric signals in back muscles: effect of side dominance. J Appl Physiol. 1994; 77:2104-2114.
8. Van Dieën JH, Oude Vrielink HH, Housheer AF, Lötters FB, Toussaint HM: Trunk extensor endurance and its relationship to electromyogram parameters. Eur J Appl Physiol. 1993; 66:388-396.

9. Farina D, Merletti R: Comparison of algorithms for estimation of EMG variables during voluntary isometric contractions. J Electromyogr Kinesiol. 2000; 10:337-350.

10. Andersson GBJ: The epidemiology of spinal disorders. In The adult spine: principles and practice. 2nd edition. Edited by Frymoyer JW. Philadelphia: Lippincott-Raven Press; 1997: 93-141.

11. NIOSH. (1997): Musculoskeletal disorders and workplace factors: A critical review of epidemiologic evidence for work-related musculoskeletal disorders of the neck, upper extremity, and low back. Department of Health and Human Services, Public Health Service, Centers for Disease Control and Prevention, National Institute for Occupational Safety and Health, DHHS, Publication No. 97-141, Cincinnati, OH: U.S.

12. Anderson CK, Chaffin D, Herrin GD: A Study of Lumbosacral Orientation under Varied Static Loads. Spine. 1986; 11:456-462.

13. McGill SM, Norman RW: Dynamically and statically determined low back moments during lifting. J Biomech. 1985; 12: 877-885.

14. Jonsson BG, Persson J, Kilbom A: Disorders of the cervicobrachial region among female workers in the electronics industry: a two-year follow-up. Int. J. Ind. Ergonomics. 1988; 3: 1-12.

15. Kilbom A, Horst D, Kemfert K, Richter A. Observation methods for eduction of load and strain on the human body - a review. Abetarskyddsstyrelsen Publikation Service. 1986; 171:92.

16. 16. Kilbom A, Persson J. Work technique and its consequences for musculoskeletal disorders. Ergonomics. 1987; 30: 273-279.

17. Ghosh T, Das B, Gangopadhyay S. Work-related Musculoskeletal Disorder: An Occupational Disorder of the Goldsmiths in India. Indian Journal of Community Medicine. 2010; 35(2): 320 - 324 .

18. Thompson SK, Mason E, Dukes S. Ergonomics and cytotechnologists, reported musculoskeletal discomfort. Diagn Cytopathol. 2003; 29(6): 364-367.

19. Huang GD, Feuerstein M. Identifying work organization targets for a work- related musculoskeletal symptom prevention program. J Occup Rehabil. 2004; 14: 13-30.

20. Kuorinka I, Kilbom BJ, Vinterberg A, et al. Standardized Nordic Questionnaire for the analysis of musculoskeletal Symptoms. Appl Ergon. 1987; 18: 233-237. 
21. McAtamney L, Corlett EN. RULA: A survey method for the investigation of work-related upper limb disorders. Appl Ergon. 1993; 24(2): 91-99.

22. Gangopadhyay S, Das B, Ghoshal G, et al. The prevalence of musculoskeletal disorder (MSD) among the prawn seed collectors of Sundarbans. J Hum Ergol. 2008; 37(2): 83-90.

23. Gangopadhyay S, Das B, Das T, Ghoshal G. An Ergonomic Study On Posture Related Discomfort Feeling Among The Pre-adolescent Agricultural Workers of West Bengal, India. Int J Occup Saf Ergon. 2005; 11(3): 315-322.

24. Gangopadhyay S, Ghosh T, Das T, Ghoshal G, Das B. Prevalence of Upper Limb Musculoskeletal Disorders among Brass Metal Workers in West Bengal, India. Ind Health. 2007; 45: 365-370.

25. Kroemer KHE. Cumulative trauma disorders: their recognition and ergonomics measures to avoid them. Appl Ergon. 1989; 20: $274-280$.

26. Hagberg $M$, Silverstein $B$, Wells $R$, et al. Work-Related Musculoskeletal Disorders (WMSDs): A Reference Book for Prevention. London: Taylor \& Francis; 1995.

27. Van W P. Design and disease. Appl Ergon. 1970; 1(5): 262 -269 .

28. Armstrong TJ, Buckle P, Fine LJ, et al. A conceptual model for work-relatedneck and upper-limb musculoskeletal disorders. Scand J Work Environ Health. 1993; 19(2): $73-74$.

29. Shirazi-Adl A, El-Rich M, Pop DG, Parnianpour M. Spinal muscle forces, internal loads and stability in standing under various postures and loads--application of kinematics-based algorithm. Eur Spine J. 2005; 14(4): 381-392.

30. Kavcic N, Grenier S, McGill SM. Quantifying tissue loads and spine stability while performing commonly prescribed low back stabilization exercises. Spine. 2004; 29: 2319 - 2329.

31. Colloca CJ, Hinrichs RN. The biomechanical and clinical significance of the lumbar erector spinae flexion-relaxation phenomenon: a review of literature. J Manipulative Physiol Ther. 2005; 28(8): 623-631.

32. Hagg G, Luttmann A. Methodologies for evaluating electromyographic field data in ergonomics. J Electromyogr. Kinesiol. 2000; 10(5): 301-312.

33. Merlitti P, Parker P. Electromyography: Physiology, Engineering and non-invasive application. 1st ed. New Jersey: John Willey and Sons; 2004: 145-153.

34. Bigland RB, Donovan EF, Roussos CS. Conduction velocity and EMG power spectrum changes in fatigue of sustained maximal efforts. J Appl Physiol. 1981; 51: 1300-1305.
35. Komi PV, Tesch P. EMG frequency spectrum, muscle structure, and fatigue during dynamic contractions in man. Eur J Appl Physiol. 1979; 42: 41-50.

36. Thorstensson A, Carlson H. Fiber types in human lumbar back muscles. Acta physiologica Scandinavica. 1987; 131: 195-202.

37. MacCance KL, Huether SE. Pathophysiology, the Biologic basis for disease in adults and children. 3rd ed. St. Louis: Mosby; 1998: 1425-1426. 